\title{
Magnetic Resonance Imaging Study on Blebs Morphology of Ahmed Valves
}

\author{
1 Joana Ferreira, ${ }^{2}$ Fernando Fernandes, ${ }^{3}$ Madalena Patricio, ${ }^{4}$ Ana Brás, ${ }^{5}$ Cristina Rios, \\ ${ }^{6}$ Ingeborg Stalmans, ${ }^{7}$ Luis Abegão Pinto
}

\begin{abstract}
Purpose: To determine the morphometric parameters of filtration blebs of a valved aqueous humor drainage device.
\end{abstract}

Materials and methods: Orbital magnetic resonances imaging (MRI) was taken after implantation of an Ahmed valve (FP7 model). Outcomes of the analysis were intraocular pressure (IOP) and the bleb's morphometric analysis (volume, height, major and minor axis). Associations between IOP and the imaging-related study variables were explored by Spearman's correlation test.

Results: Eleven patients underwent orbital MRI examination. Recordings were taken after a mean of 2.7 months (1-6 months) after surgery. IOP was significantly lower than its preoperative values $(17.6 \pm 6.4 \mathrm{~mm} \mathrm{Hg}$ vs $36.1 \pm 6.4 \mathrm{~mm} \mathrm{Hg}, \mathrm{p}<0.01)$ Mean bleb volume was $856.9 \pm 261 \mathrm{~mm}^{3}$ and its height, major and minor axis were $5.77 \pm 1.9,14.8 \pm 2.9$ and $8.14 \pm 3.6 \mathrm{~mm}$, respectively. A positive correlation was detected between IOP and mean height $(r=0.77, p=0.048)$ and major axis $(r=0.83$, $p=0.03)$. Interestingly, the overall bleb volume was related to IOP levels immediately prior to surgery $(r=0.75, p<0.01)$. Additionally, the posterior part of the plate was found to be displaced from the scleral surface in five cases $(45 \%)$.

Conclusion: Ahmed valve's bleb morphology seems to correlate with both the pre- and postoperative IOP, which might suggest a clinical benefit of administering aqueous suppressants pre- as well as postoperatively. The plate of the device may show a significant dislocation from its initial surgical implantation site.

Keywords: Glaucoma, Intraocular pressure, Bleb morphology, Ahmed valve, Magnetic resonance imaging.

How to cite this article: Ferreira J, Fernandes F, Patricio M, Brás A, Rios C, Stalmans I, Pinto LA. Magnetic Resonance Imaging Study on Blebs Morphology of Ahmed Valves. J Curr Glaucoma Pract 2015;9(1):1-5.

Source of support: Nil

Conflict of interest: None

\section{${ }^{1-5,7}$ Consultant, ${ }^{6}$ Professor \\ 1,2,7 Department of Ophthalmology, Lisbon's Hospitals, Central Lisbon, Portugal \\ ${ }^{3-5}$ Department of Neuroradiology, Lisbon's Hospitals, Central Lisbon, Portugal \\ ${ }^{6}$ Department of Ophthalmology, University Hospitals, Leuven Belgium}

Corresponding Author: Luís Abegão Pinto, Consultant Department of Ophthalmology, Lisbon's Hospitals, Central Lisbon, Alameda de Sto Antónios dos capuchos, 1169-050 Lisboa, Portugal, e-mail: abegaopinto@gmail.com

\section{INTRODUCTION}

Implantation of aqueous humor drainage devices (ADD) is an increasingly popular surgical option in glaucoma patients with noncontrolled intraocular pressure (IOP) ${ }^{1-3}$ These implants establish a drainage route for the aqueous humor from the anterior chamber into a subconjuctival reservoir. ${ }^{4,5}$ The normal functioning of this structure (known as filtering bleb) is of paramount importance for the surgical success of this surgery. ${ }^{6-8}$ However, unlike blebs seen in other filtering surgeries (such as trabeculectomies), these ADD reservoirs are not fully seen at slit-lamp due to their more posterior location. Accordingly, the standard morphological criteria for assessing a filtering bleb, such as vascularization pattern, thickness of the Tenon's capsule ${ }^{10}$ and the 'ring of steel' formation ${ }^{11}$ are of limited value since the biggest portion of the bleb remains unseen. One way to study this bleb morphology is through the use of imaging technology, such as magnetic resonance imaging (MRI). This noninvasive technology allows the characterization of the several orbital structures while still providing a high image resolution. ${ }^{12-14}$ However, the two studies where MRI has been used for this purposes refer either to a pediatric population or to a study mixing small-sized samples from two different ADD (Ahmed valve and Baerveldt tube). As these caveats precluded a wider generalization of the results, a study on an adult population in which only a single type of ADD was implanted. Accordingly, the purpose of this study was to determine the clinical correlations of MRI-bleb imaging data from glaucoma patients implanted with an Ahmed valve.

\section{MATERIALS AND METHODS}

\section{Subject Groups}

Patients with recent, uncomplicated implantation of an ADD (Ahmed Valve FP7 model, New World Medical Inc, Rancho Cucamonga, CA) on the superior temporal quadrant for an uncontrolled IOP were asked to participate in this prospective study. Inclusion criteria were the following: older than 18 years old, willing to participate in the study and having had uncomplicated surgery between 1 and 6 months before the study. Patients were excluded if possessing a connective tissue disease or orbital-related pathology (such as Graves' ophthalmopathy), having 
had a combined ADD implant procedure with cataract surgery, a background of previous ophthalmologic surgeries involving the manipulation of the orbit or extraocular muscles (e.g. strabismus, scleral buckle) or any postoperative complications (atalamia, tube erosion, plate extrusion) requiring surgical reintervention. Another exclusion criterion was the existence of contraindications to the magnetic resonance (e.g. pacemaker implant).

\section{Experimental Design}

This prospective study was conducted at the Glaucoma and Neuroradiology Department of Centro Hospitalar de Lisboa Central. This study was approved by the Local Ethics Committee and was conducted in accordance with the good clinical practice within the tents of the declaration of Helsinki. Each patient was required to sign an informed consent statement before enrolling in the study and prior to any study measurement or examination being made. At study visit, a complete ophthalmology observation was performed, which included visual acuity, IOP measurement by Goldman applanation tonometry, slit-lamp observation and fundoscopy with a 78D lens. Data from medical records detailing indication of drainage device implantation, pre-surgical IOP and current ocular hypotensive therapeutics were collected. For ethical reasons, patients were not discontinued from their regular medical therapies (IOP-related or not).

\section{Surgical Technique}

All surgeries were performed by the same surgeon (LAP), using the same technique. In brief, the surgical technique involved a fornix-based conjunctival flap in the superior temporal quadrant. The tube was primed using balanced salt solution with a 30 gauge needle. The plate was secured to the sclera with its anterior edge 8 to $10 \mathrm{~mm}$ posterior to the limbus using non-absorbable sutures $\left(8.0\right.$ nylon $\left.{ }^{\circledR}\right)$. A sclera tunnel was created starting approximately $2 \mathrm{~mm}$ from the limbus and, using a 23 gauge needle, the tunnel was advanced into the anterior chamber of the eye. The tube was trimmed bevel up and inserted through the tunnel into the anterior chamber aiming toward the center of the pupil. The tube was secured to the underlying sclera by two sutures with non-absorbable material (10.0 nylon $\left.{ }^{\circledR}\right)$. A donor scleral or corneal patch was placed over the scleral surface to cover most of the tube's path. This was sutured to the sclera with 10.0 nylon ${ }^{\circledR}$ sutures. The conjunctiva was reapposed using absorbable sutures $\left(7.0\right.$ vicry $\left.l^{\circledR}\right)$. Finally, a subtenon methylprednisolone $40 \mathrm{mg} / \mathrm{ml}$ (Depo-medrol ${ }^{\circledR}$ ) injection was performed. Postoperative treatment was a fixed combination of tobramycin and dexamethasone $\left(\right.$ Tobrade $^{\circledR}$ ) four times daily for 4 weeks.

\section{Magnetic Resonance Imaging}

Imaging data acquisition was performed in a MRI device of a Tesla (Harmony ${ }^{\circledR}$, Siemens Medical Solutions, Erlangen, Germany) using a surface coil for optimization of image capture on the same day as the study visit. Each patient was submitted to an orbital high-resolution MRI, with T1 and T2 weighted images. Axial and coronal images were captured with $2 \mathrm{~mm}$ of thickness using a $256 \times 256$ matrix over a visualization field of $210 \times 210 \mathrm{~mm}$. The Digital imaging and communications in medicine (DICOM) images were analyzed recurring to the AW Volumeshare ${ }^{\circledR} 5$ (General Electric Healthcare, Little Chalfont, United Kingdom) image processor. Images with presence of artefacts were excluded. All images were interpreted by the same observer (CR), masked to the patients' ophthalmological data. The Ahmed valve plate was identified as a low density circumlinear structure in both images T1 and T2, placed adjacent to sclera in the eyeball superotemporal quadrant. The filtration bleb, identified with a collection of humor signalled as water (high intensity on T2 images and low intensity on T1 images), was quantified using T2 images. The volumetric calculations were made using the sum of structure areas identified as filtration bleb in each coronal section where it was detected and multiplied by the thickness of each section, such as described in the literature. ${ }^{12}$

\section{Statistical Analysis}

The correlations between the analysed variables were performed recurring to the Spearman correlation. Values of $\mathrm{p}$ $<0.05$ were considered statistically significant (Graphpad Prism ${ }^{\circledR}$ ver. 5.0; Graphpad Software Inc, CA). The descriptive results are presented as the mean \pm standard deviation.

\section{RESULTS}

Table 1 summarizes the clinical and demographic information of patients included in the study. Eleven patients were included (6 males), with a mean age of $61.6 \pm 15$ years old. Tube surgery was chosen due to their specific medical history: corneal transplant (3 patients), neovascular glaucoma secondary to central retinal vein occlusion (4 patients), history of previously failed trabeculectomies ( 2 patients) and uveitic glaucoma (1 patient). IOP was significantly reduced from preoperative values of $36.1 \pm 6.4 \mathrm{~mm} \mathrm{Hg}$ to $17.6 \pm 6.4 \mathrm{~mm} \mathrm{Hg}$ at the study visit $(\mathrm{p}<0.01)$. No patient was still under topic steroid therapy. Only one patient was under topical IOP-lowering therapy (latanoprost $0.05 \%$ qd + timolol 0.5\% bid).

\section{Filtration Bleb Imaging}

The coronal sectional images analysis in T2 identified a filtration bleb mean height of $5.77 \pm 1.89 \mathrm{~mm}$ (measured in the major distance between two parallel plans at the 
Table 1: Clinical characteristic of the study patients

\begin{tabular}{lllllll}
\hline Patient & $\begin{array}{l}\text { Age } \\
\text { (years) }\end{array}$ & Gender & $\begin{array}{l}\text { Pre-op IOP } \\
(\mathrm{mm} \mathrm{Hg})\end{array}$ & $\begin{array}{l}\text { Current IOP } \\
(\mathrm{mm} \mathrm{Hg})\end{array}$ & $\begin{array}{l}\text { Time elapsed } \\
\text { (months) }\end{array}$ & Ocular comorbilities \\
\hline 1 & 32 & $\mathrm{M}$ & 43 & $35^{*}$ & 2 & Uveitic glaucoma \\
2 & 55 & $\mathrm{M}$ & 36 & 20 & 2 & Penetrating keratoplasty \\
3 & 53 & $\mathrm{M}$ & 40 & 12 & 6 & Penetrating keratoplasty \\
4 & 79 & $\mathrm{M}$ & 35 & 20 & 5 & Previous failed trabeculectomies \\
5 & 71 & $\mathrm{~F}$ & 30 & 14 & 3 & Retinal detachment (PPV) \\
6 & 85 & $\mathrm{~F}$ & 44 & 16 & 1 & Neovascular glaucoma \\
7 & 65 & $\mathrm{M}$ & 35 & 11 & 2 & Neovascular glaucoma \\
8 & 65 & $\mathrm{~F}$ & 43 & 18 & 1 & Penetrating keratoplasty \\
9 & 68 & $\mathrm{~F}$ & 37 & 16 & 3 & Previous failed trabeculectomies \\
10 & 58 & $\mathrm{~F}$ & 23 & 14 & 2 & Neovascular glaucoma \\
11 & 47 & $\mathrm{M}$ & 31 & 18 & 3 & Neovascular glaucoma \\
\hline Mean & $61.6(15)$ & - & $36.1(6.4)$ & $17.6(6.4)$ & $2.7(1.5)$ & - \\
\hline
\end{tabular}

*Patient 1 was under topical IOP-lowering medication (prostaglandin analog and nonselective beta-blocker). Pre-op: Preoperative; IOP: Intraocular pressure; PPV: Pars plana vitrectomy; M: Male; F: Female

scleral surface and at the external surface of the hyperintensive bleb component). Bleb's major axis (i.e. in sagittal direction), was $14.8 \pm 2.89$. Minor axis (i.e. in coronal direction) was $8.14 \pm 3.59 \mathrm{~mm}$. The bleb volumetric calculus registered a mean value of $859.6 \pm 261 \mathrm{~mm}^{3}$ (Table2). Interestingly, the posterior part of the plate was found to be displaced from the scleral surface in five cases. Figure 1 shows the device and filtration bleb images by MRI and slit-lamp biomicroscopy.

\section{Correlations between Imaging and Clinical Variables}

Bleb's height and major axis showed a positive correlation with postoperative IOP $(r=0.77, \mathrm{r}=0.83$; both $\mathrm{p}<$

Table 2: Volume and morphometric measurements of the filtering bleb

\begin{tabular}{llll}
\hline Volume & Vertical axis & Major axis & Minor axis \\
\hline 856.9 & 5.77 & 14.8 & 8.14 \\
$261 \mathrm{~mm}^{3}$ & $1.89 \mathrm{~mm}$ & $2.89 \mathrm{~mm}$ & $3.59 \mathrm{~mm}$ \\
\hline
\end{tabular}

Data presented as mean (SD)

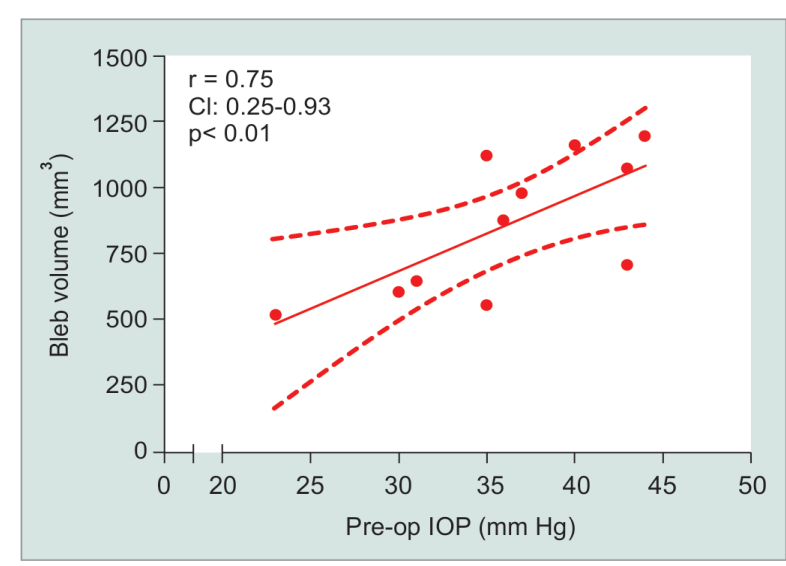

Fig. 2: Correlation between bleb volume and preoperative intraocular pressure (IOP). A positive correlation is seen between these two parameters: $r=0.75(\mathrm{Cl} 0.25-0.93), p<0.01$. Statistics performed using Spearman's correlation test

0.05). Interestingly, the bleb's overall volume correlated with the IOP levels immediately prior to surgery $(r=0.75$; $p<0.01$; Fig. 2). Neither age nor time lapse correlated with any of the imaging variables ( $\mathrm{p}>0.05$ in all comparisons).
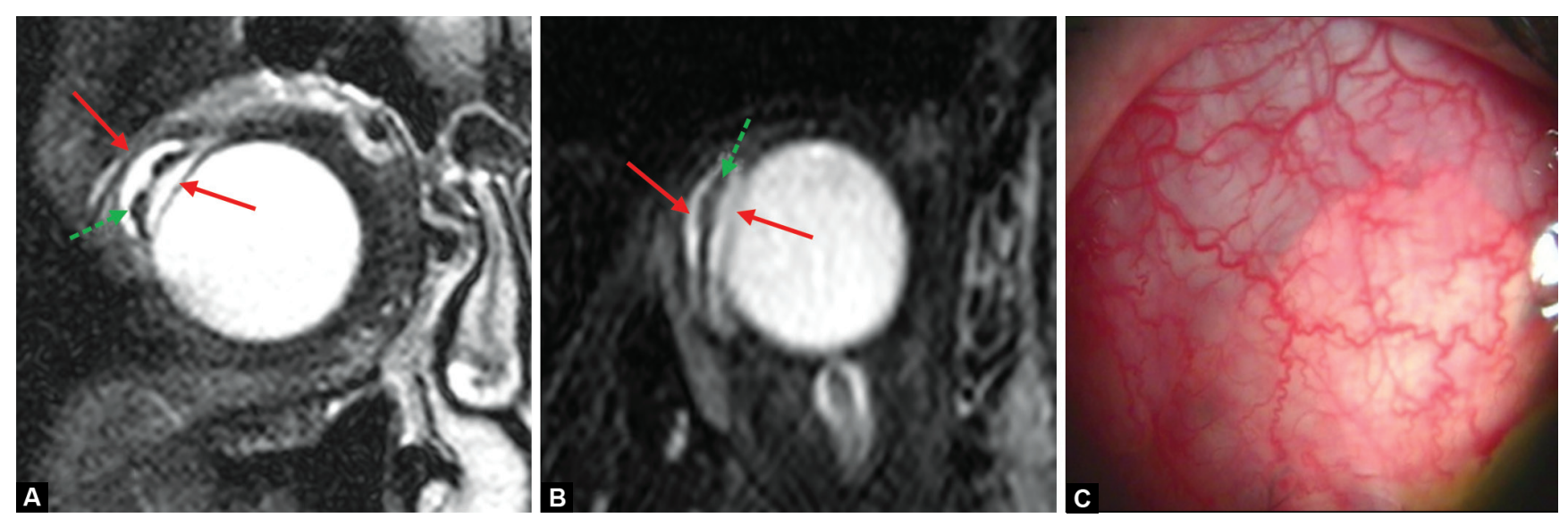

Figs $1 \mathrm{~A}$ to $\mathrm{C}$ : Example of an Ahmed valve imaging implanted in a right eye: (A and B) Depict a T2-weighted coronal and axial MRI image of a device implanted in the temporal superior quadrant. The device is the low intensity () segment (green arrow) between the two high intensity, liquid components (red arrows) of the bleb and the vitreous. This illustrates a nondirect contact between the posterior part of the plate and the scleral surface, $(\mathrm{C})$ shows the same quadrant as observed from slit-lamp biomicroscopy 


\section{DISCUSSION}

Ahmed valve's bleb morphology seems to have a particular relationship with pre- as well as postoperative IOP. In the current study, a higher preoperative IOP was associated with a higher overall bleb volume. Our results support the hypothesis that an ab initio large pressure gradient could lead to a major distension of the subconjunctival reservoir. As in any type of distension, this bleb increase can continue until a balance is reached between the pressure acting over the capsule wall and its resistance. In filtering surgery, a mechanical stress is a known factor stimulating a number of inflammatory pathways that leads to collagen deposition and increased wall thickness. ${ }^{15,16}$ This thickened wall provides increased resistance to being crossed by the aqueous humor may thus result in an IOP increase. ${ }^{17,18}$ As the aqueous humor $(\mathrm{AH})$ content of inflammatory cytokines is related to the IOP level, then at least initially, the subconjunctival space of high-IOP patients would be bathed by AH with higher concentrations of inflammatory cytokines. ${ }^{6}$ This might be an explanation as to why valved implants are associated with greater thickness of the capsular wall ${ }^{19}$ and more probability of bleb dysmorphia and creation of giant reservoirs, ${ }^{20,21}$ as nonvalved surgery is usually done resorting to techniques that prevent, at least in an early stage, a free drainage of aqueous humor. In this sense, this information would further reinforce the recent notion that early $\mathrm{AH}$ suppression may be of value in Ahmed valve implantation. A corollary of this assumption would also admit that a more aggressive decrease in preoperative IOP (with either mannitol iv or acetazolamide per os) could have decreased bleb volume. ${ }^{22}$

In addition to the bleb volumetry, its overall configuration may also be important for its IOP-lowering efficacy, as Laplace's law shows that the pressure acting on a wall would depends on the radius of its circumference. Accordingly, a reduction in the diameter of the capsule would reduce the mechanical stress on the capsule wall and thus the need to reinforce its collagen content. ${ }^{18}$ Reversely, larger bleb dimensions would be associated with a larger radius of circumference and increased wall stress, with subsequent thickened wall and higher resistance to AH reabsortion. In keeping with this concept, our data indeed show that longer, higher blebs are associated with higher IOP values.

One particular intriguing observation in our study was the luxation of the plate from their original implant site in a significant proportion of our patients. Indeed, in five patients (out of 11), the low-intensity plate was no longer placed over the sclera, but rather separated from it by a liquid layer. This plate movement-undetected at the slit-lamp-may explain why tube position inside the anterior chamber may change over time (as the posterior end of the tube may have shifted from its original location). Further studies would be needed to verify the clinical relevance of this plate luxation.

One limitation of our study is its small sample size. This is, however, the largest study on this subject, outpacing the previous study $(n=8)$. Moreover, the latter study split its numbers between two different ADD (Ahmed valves, $n=4$ and Baerveld tubes, $n=4$ ). As bleb formation may be different between various ADD models, generalization and overall comparison of the results between these studies should be done carefully. Furthermore, recruited was limited to uneventful surgeries and postoperatives. Adding in such small series a number of factors that could interfere with the healing process (such as combined cataract surgery or need for revision surgery) would have introduced a significant bias in this pilot study. Data from those more complicated surgeries would, however, be of great interest in clarifying the mechanisms behind ADD wound healing and further studies will be needed. Another limitation is the short follow-up. Of note, most patients had the MRI scans around 3 months, and the low IOP values suggest the majority of patients were no longer going through the hypertensive phase usually seen in these implants. As success rates from these ADD decline over time, it would have been interesting to perform the same analysis in patients with a longer follow-up and assess their bleb's characteristics.

\section{CONCLUSION}

MRI is a non-invasive technique that allows the evaluation of the posteriorly-located ADD bleb. Ahmed valve's bleb geometry is correlated with its IOP-lowering efficacy, and overall bleb volume is related preoperative IOP levels. The plate of the device may show a significant dislocation from its initial surgical implantation site.

\section{REFERENCES}

1. Minckler DS, Francis BA, Hodapp EA, Jampel HD, Lin SC, Samples JR, Smith SD, Singh K. Aqueous shunts in glaucoma: a report by the American Academy of Ophthalmology. Ophthalmology 2008 Jun;115(6):1089-1098.

2. Minckler DS, Vedula SS, Li TJ, Mathew MC, Ayyala RS, Francis BA. Aqueous shunts for glaucoma. Cochrane Database Syst Rev 2006 Apr;19(2):CD004918.

3. Desai MA, Gedde SJ, Feuer WJ, Shi W, Chen PP, Parrish RK 2nd. Practice preferences for glaucoma surgery: a survey of the American Glaucoma Society in 2008. Ophthalmic Surg Lasers Imaging 2011 May-Jun;42(3):202-208.

4. Minckler DS, Shammas A, Wilcox M, Ogden TE. Experimental studies of aqueous filtration using the Molteno implant. Trans Am Ophthalmol Soc 1987;85:368-392. 
5. Wilcox MJ, Minckler DS, Ogden TE. Pathophysiology of artificial aqueous drainage in primate eyes with Molteno implants. J Glaucoma 1994;3(2):140-151.

6. Molteno AC, Fucik M, Dempster AG, Bevin TH. Otago glaucoma surgery outcome study: factors controlling capsule fibrosis around Molteno implants with histopathological correlation. Ophthalmology 2003 Nov;110(11):2198-2206.

7. Loeffler KU, Jay JL. Tissue response to aqueous drainage in a functioning Molteno implant. Br J Ophthalmol 1988 Jan;72(1):29-35.

8. Classen L, Kivela T, Tarkkanen A. Histopathologic and immunohistochemical analysis of the filtration bleb after unsuccessful glaucoma seton implantation. Am J Ophthalmol 1996 Aug;122(2):205-212.

9. Clarke CK, Minassian D, Khaw PT. The more flow surgery study: the effect of intraoperative 5FU on IOP control and trabeculectomy bleb appearance using the moorfields bleb grading system. IOVS 2005;46:E-Abstract 1221.

10. Soltau JB, Rothman RF, Budenz DL, Greenfield DS, Feuer W, Liebmann JM, Ritch R. Risk factors for glaucoma filtering bleb infections. Arch Ophthalmol 2000 Mar;118(3):338-342.

11. Wong TT, Mead AL, Khaw PT. Prolonged antiscarring effects of ilomastat and MMC after experimental glaucoma filtration surgery. Invest Ophthalmol Vis Sci 2005 Jun;46(6):2018-2022.

12. Detorakis ET, Engstrom RE, Straatsma BR, Demer JL. Functional anatomy of the anophthalmic socket: insights from magnetic resonance imaging. Invest Ophthalmol Vis Sci 2003 Oct;44(10):4307-4313.

13. Detorakis ET, Maris T, Papadaki E, Tsilimbaris MK, Karantanas AH, Pallikaris IG. Evaluation of the position and function of aqueous drainage implants with magnetic resonance imaging. J Glaucoma 2009 Aug;18(6):453-459.

14. Pirouzian A, Scher C, O'Halloran H, Jockin Y. Ahmed glaucoma valve implants in the pediatric population: the use of magnetic resonance imaging findings for surgical approach to reoperation. J AAPOS 2006 Aug;10(4):340-344.

15. Molteno AC, Suter AJ, Fenwick M, Bevin TH, Dempster AG. Otago glaucoma surgery outcome study: cytology and immunohistochemical staining of bleb capsules around Molteno implants. Invest Ophthalmol Vis Sci 2006 May;47(5): 1975-1981.

16. Molteno AC, Thompson AM, Bevin TH, Dempster AG. Otago glaucoma surgery outcome study: tissue matrix breakdown by apoptotic cells in capsules surrounding molteno implants. Invest Ophthalmol Vis Sci 2009 Mar;50(3):1187-1197.

17. Kadri OA, Wilcox MJ. Surface tension controls capsule thickness and collagen orientation in glaucoma shunt devices. Biomed Sci Instrum 2001;37:257-262.

18. Wilcox M, Kadri OA. Force and geometry determine structure and function of glaucoma filtration capsules. Ophthalmologica 2007;221(4):238-243.

19. Tsai JC, Johnson CC, Dietrich MS. The Ahmed shunt versus the Baerveldt shunt for refractory glaucoma: a single-surgeon comparison of outcome. Ophthalmology 2003 Sep;110(9): 1814-1821.

20. Lai JS, Poon AS, Chua JK, Tham CC, Leung AT, Lam DS. Efficacy and safety of the Ahmed glaucoma valve implant in Chinese eyes with complicated glaucoma. Br J Ophthalmol $2000 \mathrm{Jul} ; 84(7): 718-721$.

21. Eibschitz-Tsimhoni M, Schertzer RM, Musch DC, Moroi SE. Incidence and management of encapsulated cysts following Ahmed glaucoma valve insertion. J Glaucoma 2005 Aug;14(4):276-279.

22. Pakravan M, Rad SS, Yazdani S, Ghahari E, Yaseri M. Effect of early treatment with aqueous suppressants on Ahmed glaucoma valve implantation outcomes. Ophthalmology 2014 Sep;121(9):1693-1698. 